Original Article (short paper)

\title{
Propulsion efficiency in wheelchair tennis: a case study on the influence of the racket on the handrim forces
}

\author{
Vitor Alcolea $^{1}$ (D), Guilherme da Silva Bertolaccini ${ }^{2}$ (D), Rubens Venditti Junior ${ }^{3}$ (D), \\ Fausto Orsi Medola ${ }^{2}$ \\ ${ }^{1}$ Departamento de Engenharia Mecânica, Universidade Estadual Paulista, Bauru, SP, Brazil. \\ ${ }^{2}$ Departamento de Design, Faculdade de Arquitetura, Artes e Comunicação, Universidade \\ Estadual Paulista, Bauru, SP, Brazil. \\ ${ }^{3}$ Departamento de Educação Física, Universidade Estadual Paulista, Bauru, SP, Brazil.
}

\begin{abstract}
Aims: to evaluate how the act of holding a tennis racket influences the application of forces in the handrim during manual wheelchair propulsion at a self-selected comfortable speed and sprint. Methods: A case study was conducted with an experienced wheelchair tennis player who propelled the wheelchair in a straightforward trajectory at two different velocities (self-selected comfortable speed and sprint) in two different conditions (freehand and holding the racket). Kinetic and temporal data of the pushes were obtained with the SmartWheel system attached in substitution to the conventional rear wheel at the dominant side of the player. Results: holding the racket affects the propulsion pattern mainly when an accelerated movement is required (sprint). Compared to the propulsion at a self-selected speed, propelling the chair as fast as possible with the racket in hands resulted in lower total and tangential forces on the handrim, and decreased push time and increased push frequency. Conclusion: Such influence on both kinetic and temporal propulsion impact the mechanical efficiency of the manual wheelchair propulsion, which may, ultimately, affect the sport's performance. Special attention should be directed to the propulsion training with the racket in maneuvers and motions that are characteristic of the wheelchair tennis match in an attempt to provide the athlete with proper technique for optimal propulsion efficiency and sports performance.
\end{abstract}

Keywords: wheelchair tennis, manual propulsion, kinetics, mobility, assistive technology, rehabilitation engineering.

\section{Introduction}

Manual wheelchairs have been used as the main means of mobility by many people with disabilities that have affected the ability to walk. The long-term use of manual wheelchairs has been associated with a high prevalence of injuries due to the biomechanical loads on the upper $\operatorname{limbs}^{1,2}$. Alternative modes of manual propulsion such as lever-propulsion mechanisms ${ }^{3}$ and power assistance system ${ }^{4-7}$ have been proposed to reduce biomechanical loads in manual wheelchair mobility. Despite the potential benefits of these systems, still, manual propulsion remains the main means of independent mobility with manual wheelchairs.

When it comes to the use of wheelchairs in sports practice, the prevalence of shoulder complaints is relatively high, with pain being the most common in wheelchair athletes ${ }^{8}$. This context highlights the need for initiatives to preserve upper limb function. The proper wheelchair prescription and configuration, training of propulsion technique and muscle strengthening are factors that influence the propulsion efficiency and may contribute to the safe wheelchair usage $e^{9-12}$.
The practice of wheelchair sports has been associated with psychosocial well-being ${ }^{13,14}$, benefits in physical self-esteem ${ }^{15}$, psychosocial and quality of life ${ }^{16}$. The adaption to the practice of Paralympic sports often requires the user to equate the ambulation mode and the sport technique in a way to achieve optimal performance in the sport modality. In the case of Wheelchair Tennis, the challenge is to coordinate the upper limbs' actions of propelling the chair, while holding the racket and hitting the ball. The pace of the match, especially in high competitions, demands a high level of physical conditioning, manual wheelchair propulsion skills, and sports technique.

Recent research on wheelchair tennis has addressed the effect of prior tennis experience on players' visual search strategies ${ }^{17}$, physiological responses during a match $^{18}$, and equipment configuration for optimal mobility performance $\mathrm{e}^{19}$.

The study of de Groot $e t$ al. ${ }^{20}$ found that the racket negatively affects the propulsion technique and may expose the upper limbs to injuries. According to the authors, the increased time spent for the coupling of the hand with the racket to the handrim results in power losses during submaximal and sprint tests on a wheelchair erg- 
ometer. More recently, the use of a square-profile design of wheelchair handrim did not improve propulsion technique while holding a tennis racket ${ }^{21}$. Although both studies were carried out in stationary conditions (less representative of propulsion in real contexts), they highlight the negative influence on propulsion technique while propelling the wheelchair with the racket in hands, suggesting the need for further innovation in handrim designs.

In the current case study, we investigated how the act of holding a racket influences the efficiency of manual wheelchair propulsion over the ground at two different velocities: self-selected and sprint mode.

\section{Methods}

This is a case study research design. One experienced male wheelchair tennis player (59 years old, the weight of $83 \mathrm{~kg}$, the height of $1.76 \mathrm{~m}$ ), with impaired function of the lower limbs due to Adrenoleukodystrophy, voluntarily participated in this study. The Research Ethical Committee of the School of Architecture, Arts and Communication - FAAC/UNESP (Process 800.500), previously approved all the study procedures.

To measure propulsion forces and wheel motion, the instrumented wheel, SmartWheel (Three Rivers Holdings, Mesa, AZ, USA) was installed in the place of the right rear wheel of a rigid frame wheelchair (model Star Lite, Ortobras), as the participant was right-handed.

The participant performed two sets of straightforward propulsion (self-selected speed and sprint at maximum speed) in two different situations: holding the tennis racket (dominant side), and freehand (without the racket). For all the situations, the participant was asked to perform four forward pushes followed by a fifth action of breaking the chair. Each task was repeated three times in a row. A summary of the dependent variables measured with the SmartWheel system is presented in Table 1. The propulsion trials were all carried out on a flat and smooth cemented floor.

Table 1 - Kinetic variables measured with the SmartWheel system.

\begin{tabular}{|c|c|}
\hline Dependent variables & Definition \\
\hline PeakFtot $[N]$ & Maximum force exerted during a touch \\
\hline PeakMz $[\mathrm{N} * \mathrm{~m}]$ & Maximum moment value in the $\mathrm{Z}$ axis \\
\hline PeakFt $[N]$ & Maximumtangential force \\
\hline Ave Ftot $[\mathrm{N}]$ & Average of the total force \\
\hline Ave Ft $[\mathrm{N}]$ & Average of the tangential force \\
\hline $\begin{array}{l}\text { Peak / Average Force } \\
\text { Ratio }\end{array}$ & Peak force divided by the average force \\
\hline $\begin{array}{l}\text { Mechanical Effec- } \\
\text { tiveness }\end{array}$ & $\begin{array}{l}\text { Proportion of the total force used to effectively } \\
\text { move the chair forward }\end{array}$ \\
\hline PushPeriod Time & $\begin{array}{l}\text { Time spent with the hand on the rim when push- } \\
\text { ing }\end{array}$ \\
\hline PushFrequency & Number of pushes per second \\
\hline
\end{tabular}

The Smartwheel data was organized in a datasheet (Microsoft Excel2016 for Windows, Microsoft, Redmond, WA, USA) and analyzed descriptively by means of the mean and standard deviation of the three trials for each of the two conditions (freehand and with racket) and velocities (self-selected and sprint). The propulsion forces were synchronized taking as reference the peak force of the first push.

\section{Results}

When comparing straightforward propulsion at a self-selected comfortable speed in freehand and holding the racket modes, we found a very similar propulsion pattern in terms of force intensity and push contact (Figure 1). Conversely, when propelling the wheelchair at maximum speed (sprint mode), the holding racket mode showed forces of lower intensity and shorter durations of push contacts, thus affecting the mechanical efficiency of manual propulsion (Figure 2). The pattern observed in the tangential force in the first and the three subsequent forward pushes reveal a progressive loss of power and push contact. In the last (fourth) push, the force magnitude and push duration drop to around half of the force applied in the first push. In the freehand mode, both force intensity and push time maintain similar levels in all the forward

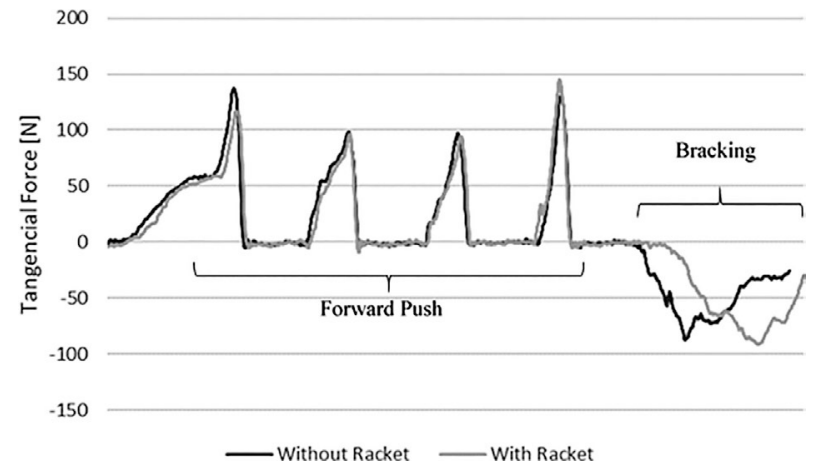

Figure 1 - Self-selected velocity in freehand (without racket) and holding racket (with racket) conditions.

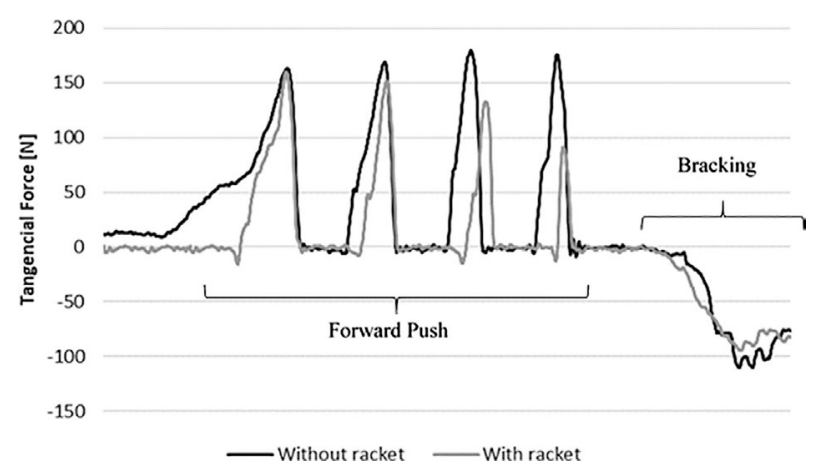

Figure 2 - Tangential force measured by SmartWheel. Comparison between accelerated straight maneuvers with and without racquet. 
pushes (of course, the first push has a singular pattern to put the wheelchair in motion).

In the sprint task (Figure 2), the first push shows an initial ramp of increasing force (preparation) followed by a rapid increase of force when propelling the chair with freehand. Conversely, with the racket in hand, push preparation does not exist, thus leading to the need for an acute ramp of force application in a shorter time.

We found lower values of average tangential forces with the racket in hand for both self-selected speed and sprint (Table 2) of around $80 \%$, which resulted in a propulsion mechanical effectiveness (Table 3 ) of $91.20 \%$ for selfselected speed and $90 \%$ of the sprint in relation to the mechanical effectiveness of the situation without the racket. In terms of the propulsion dynamics, the push frequency with the racket in hand was increased by $13.33 \%$ for the sprint mode and decreased in $2.38 \%$ when propelling at a self-selected speed, in comparison to the freehand mode.

\section{Discussion}

The act of holding a racket while pushing the wheels forward affected propulsion efficiency in the sprint mode by reducing the handrim contact. Short bouts of rapid movement are the most prevalent mobility actions in the context of a tennis match. Therefore, the influence of the racket on propulsion efficiency may have implications for sport's performance. Investigating the factors that influence propulsion kinetics in different maneuvers and actions that are characteristic of wheelchair tennis may provide information on how to improve overall athlete's performance, as well as to reduce the risk of upper limb injuries. The study of de Groot et al. ${ }^{20}$ highlighted the negative influence of the act of holding a racket on propulsion patterns and the possible risk of upper limb injuries.
The current study also revealed a progressive loss of power and the duration of push contact in the sprint mode and racket in hand, suggesting a progressive increase in the difficulty for the athlete to keep accelerating the wheelchair while holding the racket. Specifically, the racket seems to increase the difficulty to a couple in a stable way the hand on the handrim of a rotating wheel. Higher levels of propulsion forces in start-up compared with steady-state propulsion are expected, as shown by the study of Koontz et al. ${ }^{22}$, as a result of the inertial challenge to put the chair in motion.

In terms of the propulsion dynamics, the push frequency with the racket in hand was increased by $13.33 \%$ for the sprint mode and decreased in $2.38 \%$ when propelling at self-selected velocity, in comparison to the freehand mode. Possibly, such different results from the push time, which refers to the duration the user keeps the hands on the handrim while pushing the wheels forward. When propelling the wheelchair at a self-selected speed, the average push time was very similar for both freehand $(1.25 \mathrm{~s})$ and holding the racket $(1.28 \mathrm{~s})$; while for the sprint, the push time while holding the racket was reduced to $77.31 \%$ of the push time without the racket. Therefore, there is an association between push time and frequency: shorter push times require a higher push frequency to compensate in an attempt to maintain the desired velocity. Corroborating with this finding, the study of Yang et $a l^{23}$ has shown that greater push times are associated with lower push frequencies.

Finally, this result demonstrates that the impact of the act of holding the racket is more intense in mobility situations that require accelerating the wheelchair, which is the case of the wheelchair tennis sport modality. There is, therefore, the need for innovative proposals for the design of wheelchair handrim that optimize the stability in

Table 2 - Average propulsive forces (measured by the SmartWheel system), in two trajectories of movement, with and without the racket in the right hand.

\begin{tabular}{lcccccc}
\hline Mode & Trajectory & Peak Ftot $[\mathrm{N}]$ & Peak Mz $[\mathrm{N*m}]$ & Peak Ft $[\mathrm{N}]$ & Ave Ftot $[\mathrm{N}]$ & Ave Ft $[\mathrm{N}]$ \\
\hline \multirow{2}{*}{ Without racket } & Self-selected velocity & 107.56 & 30.17 & 117.3 & 60.8 & 62.33 \\
Without racket & Sprint & 144.85 & 42.34 & 164.64 & 86.33 & 90.41 \\
With racket & Self-selected velocity & 90.79 & 24.23 & 94.19 & 54.4 & 48.98 \\
With racket & Sprint & 151.19 & 34.41 & 133.78 & 92.45 & 75.82 \\
\hline
\end{tabular}

Table 3 - Average push characterization (measured by the SmartWheel system), in two movement trajectories, with and without the racket in the right hand.

\begin{tabular}{lccccc}
\hline Mode & Trajectory & Push period [s] & Push frequency [1/s] & Mechanical effectivness & Peak/average force ratio \\
\hline Without racket & Self-selected velocity & 1.25 & 0.84 & 0.91 & 1.9 \\
Without racket & Sprint & 0.97 & 1.2 & 0.9 & 2.01 \\
With racket & Self-selected velocity & 1.28 & 0.82 & 0.83 & 1.81 \\
With racket & Sprint & 0.75 & 1.36 & 0.81 & 1.75 \\
\hline
\end{tabular}


the coupling between the hand with the racket and the rim and propulsion efficiency.

\section{Conclusions}

This study found that holding a racket can negatively affect the performance of wheelchair tennis by affecting the efficiency of manual propulsion. We found that, while holding a racket and propelling as fast as possible (sprint mode), the push time is decreased and, as result, the push frequency increases to compensate it and maintain the velocity. On the other hand, in a comfortable propulsion at self-selected velocity, both push time and frequency are very similar for the situations with and without the racket, which indicates that the act of holding the racket is more prejudicial for the propulsion efficiency in the situation when the user needs to accelerate and impose a rapid increase in the velocity, which is the case of most of the situations in a wheelchair tennis match. Therefore, it is important to provide manual propulsion training exploring a diversity of maneuvers that are characteristic of the wheelchair tennis practice, with the goal of achieving the optimal balance between propulsion efficiency and sports performance. Additionally, the development of accessories and devices to optimize the coupling between the hand (with the racket) and the handrim might contribute to improving the agility with the wheelchair in a tennis match.

\section{Acknowlegdments}

This research was funded by FAPESP (São Paulo Research Foundation), grant no. 16/05026-6 and 17/ 14177-0.

\section{References}

1. Alm M, Saraste H, Norrbrink, C. Shoulder pain in persons with thoracic spinal cord injury: prevalence and characteristics. J Rehabil Med. 2008;40(4):277-83.

2. Curtis KA, Drysdale GA, Lanza RD, Kolber M, Vitolo RS, West R. Shoulder pain in wheelchair users with tetraplegia and paraplegia. Arch Phys Med Rehabil. 1999;80(4):453-7.

3. Lui J, MacGillivray MK, Sheel AW, Jeyasurya J, Sadeghi M, Sawatzky BJ. Mechanical efficiency of two commercial lever-propulsion mechanisms for manual wheelchair locomotion. J Rehabil Res Dev. 2013;50(10): 1363-72.

4. Medola FO, Bertolaccini GS, Silva SRM, Lahr GJG, Elui VMC, Fortulan CA. Biomechanical and perceptual evaluation of the use of a servo-controlled power-assistance system in manual wheelchair mobility. International Symposium on Medical Robotics (ISMR). 2018, p. 1-5.

5. Lahr GJG, Medola FO, Sandnes FE, Elui, VMC, Fortulan CA. Servomotor assistance in the improvement of manual wheelchair mobility. Stud Health Technol Inform. 2017;242:786-92.
6. Medola FO, Purquerio BM, Elui VM, Fortulan CA. Conceptual project of a servo-controlled power-assisted wheelchair. In: IEEE RAS \& EMBS International Conference on Biomedical Robotics and Biomechatronics. 2014, 450-454.

7. Lighthall-Haubert L, Requejo PS, Mulroy SJ, Newsam CJ, Bontrager E, Gronley JK, Perry J. Comparison of shoulder muscle electromyographic activity during stand-ard manual wheelchair and push-rim activated power assisted wheelchair propulsion in persons with complete tetraplegia. Arch Phys Med Rehabil. 2009;90(11):1904-15.

8. Heyward OW, Vegter RJK, de Groot S, van der Woude LHV. Shoulder complaints in wheelchair athletes: A systematic review. PLoS ONE. 2017;12(11).

9. Bertolaccini GDS, Carvalho Filho IFP, Christofoletti G, Paschoarelli LC, Medola FO. The influence of axle position and the use of accessories on the activity of upper limb muscles during manual wheelchair propulsion. Int J Occup Saf Ergon. 2018;24(2):311-15.

10. Morgan KA, Tucker SM, Klaesner JW, Engsberg JR. A motor learning approach to training wheelchair propulsion biomechanics for new manual wheelchair users: A pilot study. J Spinal Cord Med. 2015;40(3):304-15.

11. Tørhaug T, Brurok B, Hoff J, Helgerud J, Leivseth G. The effect from maximal bench press strength training on work economy during wheelchair propulsion in men with spinal cord injury.Spinal Cord. 2015;54(10):838-42.

12. Cherubini M, Melchiorri G. Descriptive study about congruence in wheelchair prescription. Eur J Phys Rehabil Med. 2015;48(2):217-22.

13. Richardson EV, Papathomas A, Smith B, Goosey-Tolfrey VL. The psychosocial impact of wheelchair tennis on participants from developing countries. Disabil Rehabil. 2015;39 (2):193-200. doi: 10.3109/09638288.2015.1073372.

14. Sporner ML, Fitzgerald SG, Dicianno BE, Collins D, Teodorski E, Pasquina PF, Cooper RA. Psychosocial impact of participation in the National Veterans Wheelchair Games and Winter Sports Clinic. Disabil Rehabil. 2009;31(5):41018. doi: 10.1080/09638280802030923.

15. Qasim S, Telfah Y, Haddad Y. Physical self-esteem of wheelchair basketball players. Acta Gymnica, published online ahead of print. 2019; 49(1):3-9. doi: 10.5507/ ag.2018.025.

16. Medola FO, Busto RM, Marçal ÂF, Junior AA, Dourado AC. Sports on quality of life of individuals with spinal cord injury: A case series. Rev Bras Med Esporte. 2011;17 (4): 254-256.

17. Hunfalvay M, Murray N. The Effect of Prior Tennis Experience on Wheelchair Tennis Players' Visual Search. Adapt Phys Act Q. 2018;35(4):329-341.

18. Roy JLP, Menear KS, Schmid MMA, Hunter GR, Malone LA. Physiological responses of skilled players during a competitive wheelchair tennis match. J Strength Cond Res. 2006;20(3):665-671.

19. Mason BS, Porcellato L, van der Woude LHV, Goosey-Tolfrey VL. A qualitative examination of wheelchair configuration for optimal mobility performance in wheelchair sports: A pilot study. J Rehabil Med. 2010;42: 141-49.

20. de Groot S, Bos F, Koopman J, Hoekstra AE, Vegter RJK. Effect of holding a racket on propulsion technique of 
wheelchair tennis players. Scand J Med Sci Sports. 2017;27 (9):918-24.

21. de Groot S, Bos F, Koopman J, Hoekstra AE, Vegter RJK. The effect of a novel square-profile hand rim on propulsion technique of wheelchair tennis players. Applied ergonomics. 2018;71:38-44.

22. Koontz AM, Cooper RA, Boninger ML, Yang Y, Impink BG, van der Woude LHV. A kinetic analysis of manual wheelchair propulsion during start-up on select indoor and outdoor surfaces. J Rehabil Res Dev. 2005;42(4):447-58.

23. Yang YS, Koontz AM, Yeh SJ, Chang JJ. Effect of backrest height on wheelchair propulsion biomechanics for level and uphill conditions. Arch Phys Med Rehabil. 2012;93:654659.
Corresponding author: Fausto Orsi Medola address: Av. Eng. Luís Edmundo Carrijo Coube, 14-01, Nucleo Hab. Pres. Geisel, Bauru, SP, Brasil. Email: fausto. medola@unesp.br.

Manuscript received on September 24, 2019

Manuscript accepted on January 27, 2020

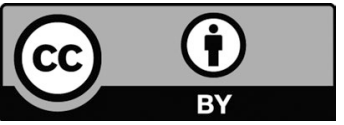

Motriz. The Journal of Physical Education. UNESP. Rio Claro, SP, Brazil - eISSN: 1980-6574 - under a license Creative Commons - Version 4.0 